\title{
BMJ Open Qualitative evaluation of primary care providers' experiences caring for frequent users of the emergency department
}

\author{
Laureline Brunner (D) , ${ }^{1}$ Marina Canepa Allen, ${ }^{1}$ Mary Malebranche, ${ }^{2}$ \\ Catherine Hudon (D), ${ }^{3}$ Nicolas Senn, ${ }^{4}$ Olivier Hugli (D) , ${ }^{5}$ Francis Vu, ${ }^{1}$ \\ Christina Akré, ${ }^{6}$ Patrick Bodenmann ${ }^{1}$
}

To cite: Brunner L, Canepa Allen M, Malebranche M, et al. Qualitative evaluation of primary care providers' experiences caring for frequent users of the emergency department. BMJ Open 2021;11:e044326. doi:10.1136/ bmjopen-2020-044326

- Prepublication history and additional supplemental material for this paper are available online. To view these files, please visit the journal online (http://dx.doi.org/10.1136/ bmjopen-2020-044326).

$\mathrm{CA}$ and $\mathrm{PB}$ contributed equally.

Received 30 August 2020 Accepted 02 June 2021

Check for updates

(C) Author(s) (or their employer(s)) 2021. Re-use permitted under CC BY-NC. No commercial re-use. See rights and permissions. Published by BMJ.

For numbered affiliations see end of article.

Correspondence to

Laureline Brunner;

laureline.brunner@unil.ch

\section{ABSTRACT}

Objectives Many interventions have been developed over the years to offer frequent users of the emergency department (FUEDs) better access to quality coordinated healthcare. Despite recognising the role primary care physicians (PCPs) play in FUEDs' care, to date their perceptions of case management, the most studied intervention, have rarely been assessed. Furthermore, a gap regarding PCPs' experience of caring for FUEDs persists. Thus, this study aimed to explore PCPs' perceptions of the care provided to FUEDs in emergency and primary care settings, their views on the local case management team (CMT), and their suggestions to improve FUEDs' care.

Design Qualitative study using in-depth semistructured interviews and inductive thematic analysis.

Setting Canton of Vaud, Switzerland.

Participants Thirty PCPs participated, 16 in private practice (PP-PCPs) and 14 based at the Lausanne University Centre of General Medicine and Public Health (Unisanté-U-PCPs).

Results U-PCPs and PP-PCPs thought that most FUEDs' emergency department (ED) visits were legitimate, but questioned ED adequacy to meet FUEDs' needs. Yet, both PCP groups reported encountering many challenges in FUEDs' care themselves. In this context, PP-PCPs seemed more satisfied of the care they provided to FUEDs than U-PCPs. Generally, U-PCPs seemed to find more value in the CMT to help them care for FUEDs than PP-PCPs. To enhance FUEDs' care, U-PCPs and PP-PCPs suggested enhancing collaboration with other healthcare providers. U-PCPs also wished to increase their availability, and some PP-PCPs considered outpatient clinics, larger group practices or medical centres most appropriate to handle FUEDs' needs.

Conclusions This study highlights the many challenges PCPs face in caring for FUEDs, that a CM intervention has the potential to mitigate, and provides ways forward in improving FUEDs' care, including reinforced communication with the CMT and ED physicians, and structural changes to their own way of delivering care to FUEDs.

\section{INTRODUCTION}

Frequent users of the emergency department (FUEDs) are a heterogeneous group of

\section{Strengths and limitations of this study}

- This study provides unique and novel insights into the perceptions of primary care physicians (PCPs) as key stakeholders in frequent users of the emergency department (ED)' care.

- Selecting PCPs who had contact with the case management team (CMT) between 2010 and 2018 may have led to a recall bias.

- The specific case management (CM) context on which the study findings are based might involve different types of PCPs with different relationships and communication modes with the CMT and ED physicians than in other $\mathrm{CM}$ interventions, thus limiting the comparison with other CM contexts.

individuals that account for a disproportionate number of all emergency department (ED) visits in western countries. ${ }^{12}$ FUEDs represent $4.5 \%-8 \%$ of ED patients accounting for $21 \%-28 \%$ of ED attendance. ${ }^{3}$ Understanding the causes for frequent ED use among this population, and designing interventions to address driving factors, has been the focus of an ever-growing body of literature. ${ }^{2-8}$ One key finding is that frequent ED use may be a symptom of failures to provide continuity, accessibility and coordination of care for these complex and multimorbid patients. ${ }^{5}{ }^{9-11} \mathrm{~A}$ well-studied intervention to improve FUEDs' healthcare coordination is case management (CM) ${ }^{812} \mathrm{CM}$ can be described as 'a collaborative approach to ensure, coordinate, and integrate care and services for patients, in which a case manager evaluates, plans, implements, coordinates, and prioritises services on the basis of patients' needs in close collaboration with other healthcare providers'. ${ }^{13}$

In 2010, a CM team (CMT) was jointly created by the Lausanne University Hospital and the Lausanne University Centre of General Medicine and Public Health (Unisanté), located in the Canton of Vaud 
with a population of approximately $800000 .{ }^{14}$ This CMT was part of an extensive research project aimed at characterising the local FUEDs-defined as making $\geq 5 \mathrm{ED}$ visits per year, using a validated definition ${ }^{15}{ }^{16}$ —and improving their care coordination and health outcomes. ${ }^{15} 17$ The CMT objectives were (1) to offer FUEDs better access to high-quality coordinated healthcare, and (2) to facilitate patients' empowerment and self-confidence in managing their own health-related concerns. ${ }^{18}$ Although the intervention was hospital-based, the CMT aimed to collaborate with primary care physicians (PCPs), recognising the integral role they play in providing care for FUEDs. ${ }^{15}$

Despite the key role PCPs play in supporting FUEDs, ${ }^{19} 20$ to date there has been limited exploration of their perceptions of CM interventions for FUEDs. Furthermore, there is a gap in the literature regarding PCPs' experience in caring for FUEDs. To address these gaps, this study addressed three questions:

1. What do PCPs think of the care provided to their FUEDs in emergency and primary care settings?

2. What are PCPs' views of the CM intervention and the CM team?

3. What can PCPs suggest to improve FUEDs' care?

\section{METHODS}

\section{Design}

A qualitative descriptive approach was chosen using semistructured interviews with PCPs in order to gather extensive information and enable rich description of PCPs' experiences in caring for FUEDs, by interpreting findings staying as close as possible to the literal description of the original data. ${ }^{21} 22$

\section{Setting}

The CMT consisted of three nurses working under medical supervision. Once FUEDs were identified in the ED, CMT nurses proposed them enrolment, after evaluating their vulnerability, using a validated questionnaire. $^{2}$ CMT nurses offered FUEDs two interventions, which varied mainly in length (a few meetings to years of follow-up) and communication means (phone calls, e-mails, letter), according to the complexity of their situation. A detailed description of the CMT, the vulnerability assessment and CM interventions are provided in online supplemental appendix 1 .

While performing the $\mathrm{CM}$ intervention, $\mathrm{CM}$ nurses interacted with two kinds of PCPs: PCPs working in private practice (PP-PCPs) and residents/fellows working as PCPs at Unisanté (U-PCPs) while obtaining subspecialised training in other areas of medicine. PP-PCPs are independent physicians, most of them working alone, some in group practices or in medical centres (larger practices shared by PCPs and other medical specialties with in-house multidisciplinary supports), who bill their services on a fee-for-service basis, according to the Swiss pricing system for medical services (TARMED). ${ }^{23}$ In contrast, U-PCPs work as employees of an institution
(Unisanté), which pays them a fixed salary. U-PCPs work at Unisanté for approximately 12-18 months.

\section{Participants and recruitment}

Participants included PP-PCPs and U-PCPs of FUEDs recruited in the CM intervention between January 2010 and December 2018. Participants were identified through the CM intervention database. This database includes sociodemographic and intervention-related data on each patient involved in the CM intervention since its inception, including the name of each patient's PCP at the time of the intervention. A purposive sampling strategy ${ }^{24}$ was used to recruit PCPs representing both private practice and Unisanté settings to facilitate comparisons between these two settings. For U-PCPs, this purposive sampling strategy involved ensuring PCPs represented perspectives from each year of the CM intervention. As such, U-PCPs did not need to be still working at Unisanté at the time of the study to be included. PCPs were excluded if they could not be contacted, were retired, were coauthors in this study, or if their patients did not consent to their involvement in the CM intervention. Invitations to participate in the study were initiated by phone calls to individual practices, with follow-up e-mails when requested. Figure 1 represents a flow diagram outlining the recruitment process for study participants. ${ }^{24}$

\section{Data collection}

Data were collected through in-depth semistructured interviews conducted by LB (doctoral student), who received training on interview methods. The interviewer did not know the interviewees prior to the study. Interview structure was based on a grid created by coauthors to ensure key topics were addressed. Topics included: (1) challenges encountered in FUEDs' care and solutions to address them; (2) collaboration with the CMT and suggestions for enhancing collaboration; (3) tools needed to provide better care for FUEDs. The interview guide is available in online supplemental appendix 2. Interviews were conducted until theoretical saturation was reached. ${ }^{21}$ The first three interviews were used to pilot test the interview guide. As the guide was only slightly modified following the pilot test, these interviews were included with the others for analysis. ${ }^{25}$ Interviews were recorded, anonymised and transcribed verbatim in French. During the interviews, participants completed a short sociodemographic form including their age, gender, year of medical school graduation, and whether they worked alone or in a group practice (for PP-PCPs). Each participant provided written informed consent.

\section{Data analysis}

Data were analysed using an inductive approach, as no predefined framework was imposed on the data. ${ }^{26}$ Thematic analysis was chosen in order to identify common themes without limiting the importance of the themes to the frequency at which they occurred. ${ }^{27}$ Analysis of PP-PCPs and U-PCPs' interviews was conducted separately 


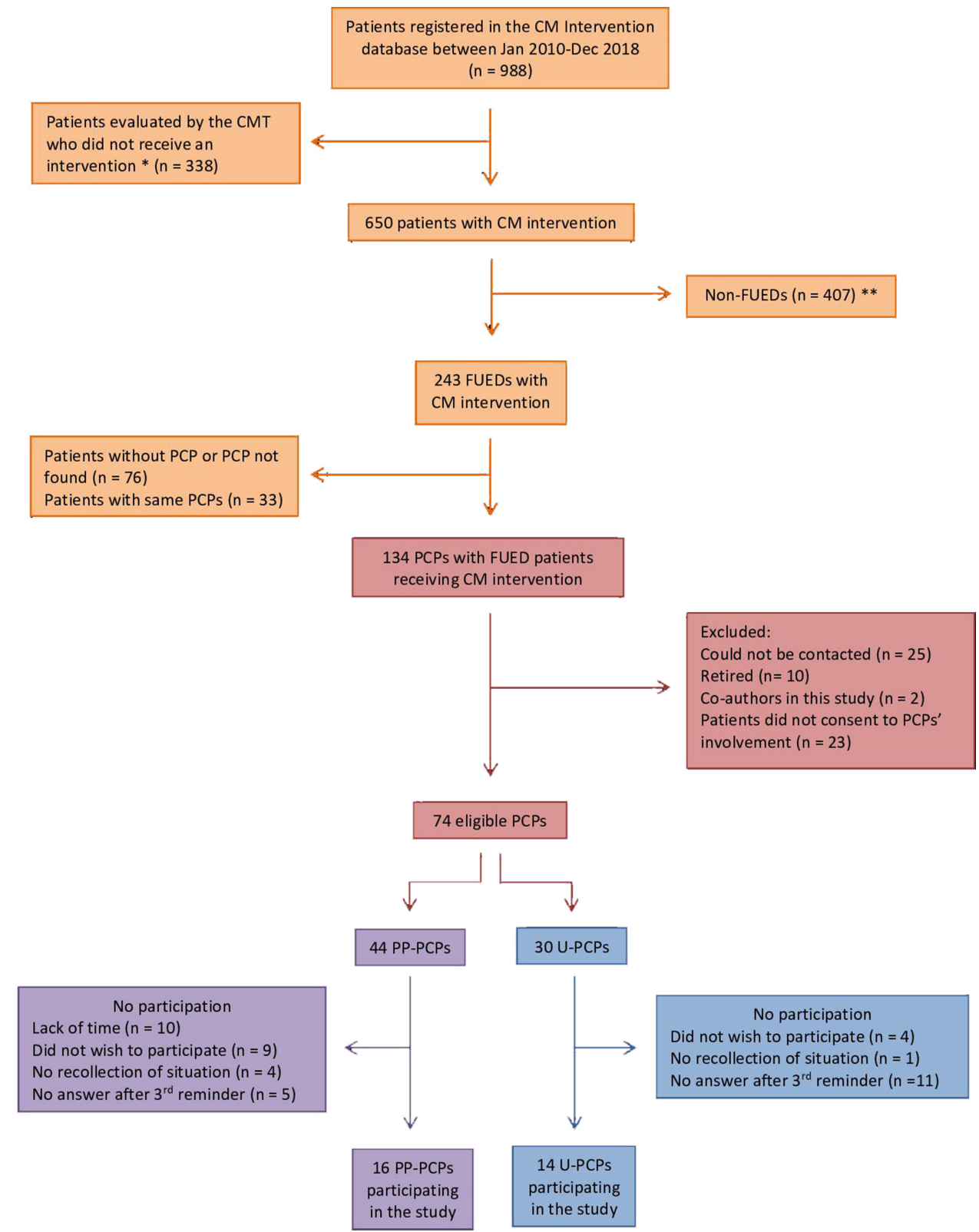

Figure 1 Diagram of process leading to eligible participants in the study. ${ }^{*}$ Patients did not fill out the vulnerability criteria (see online supplemental appendix 1) or decision was made with the existing healthcare network not to intervene; ${ }^{* *}$ the case management team (CMT) also intervenes with vulnerable patients who are not frequent users of the emergency department (FUEDs), whom were excluded from this study (see online supplemental appendix 1). CM, case management team; PCP, primary care physician; PP-PCPs, PCPs working in private practice; U-PCPs, PCPs at Unisanté.

to ensure a comprehensive overview and enable comparison of their experiences. Interviews were coded by LB using MaxQDA2018 software for qualitative analysis. A crosscheck of the codes to ensure validity was performed by MCA, who had a background in CM interventions for FUEDs. Analysis then permitted the identification of themes that addressed the three research questions. Discussions between these two authors were held until consensus on the themes was reached. Relevant quotes were translated to English by LB.

\section{Patient and public involvement}

Patients and public were not involved in our study. However, we believe that voicing the perceptions of key stakeholders involved in FUEDs' care such as PCPs is a way forward in improving FUEDs' care.

\section{RESULTS}

Between April and July 2019, 30 semi-structured in-person interviews were conducted with 16 PP-PCPs and 14 U-PCPs. All interviews lasted $30-45 \mathrm{~min}$ depending on PCPs' availability. All interviews were recorded except one at the request of the PCP. The sociodemographic characteristics of participating PCPs are presented in table 1.

Results were organised according to the three research questions. Overall, PP-PCPs reported similar experiences 


\begin{tabular}{|c|c|}
\hline Characteristics & Total $(n=30)$ \\
\hline Age (years), mean (IQR) & $46.5(32-64)$ \\
\hline \multicolumn{2}{|l|}{ Gender (\%) } \\
\hline Female, $\mathrm{n}$ & $15(50 \%)$ \\
\hline $\begin{array}{l}\text { Year of medical school graduation, mean } \\
\left(I Q R^{\star}\right)\end{array}$ & 1998 (1979-2010) \\
\hline PP-PCPs, n (\%) & $16(53 \%)$ \\
\hline Individual practice & $6(37.5 \%)$ \\
\hline Group practice or medical centre & $10(62.5 \%)$ \\
\hline U-PCPs, n (\%) & 14 (47\%) \\
\hline
\end{tabular}

*IQR, interquartile range

PP-PCPs, PCPs working in private practice; U-PCPs, PCPs at Unisanté.

when caring for FUEDs despite working in diverse settings (ie, alone in an independent practice, in a group practice or in a medical centre). Therefore, their results were grouped under 'PP-PCPs' with differences highlighted when relevant.

\section{PCPs' views of the care provided to FUEDs in emergency and primary care settings}

See table 2 for a summary of the main themes that emerged in subsection 1 with illustrative quotes.

\section{U-PCPs}

When caring for FUEDs, U-PCPs reported encountering many challenges. An important challenge was ensuring regular follow-ups with FUEDs, due to missed appointments, unexpected arrivals at the clinic with urgent needs, or FUEDs 'alternately disappearing and reappearing' (U-PCP14) from follow-up. Other challenges noted by U-PCPs in addressing FUEDs' care needs included the part-time nature of their work, their short-term contract at Unisanté, their 'overbooked agendas' (U-PCP9) and inflexible working hours. Further challenges included migrant patients not understanding the purpose of having a PCP, complicated coordination for complex somatic patients, a lack of social work support, and unrealistic patient expectations. Patient-related and structurerelated challenges were interpreted as reasons that could lead FUEDs to visit the ED.

U-PCPs explained that FUEDs with irregular follow-ups could see the ED as a reference point or prefer the ED 24/7 opening hours as opposed to Unisanté planned consultations. U-PCPs also mentioned that FUEDs might not differentiate them from ED physicians, due to their short rotation at Unisanté and little availability. However, U-PCPs differed on their views of FUEDs' ED visits legitimacy and adequacy.

Some U-PCPs considered that many FUEDs' ED visits were not 'medical emergencies' (U-PCP9), most notably those made for social reasons. Others considered FUEDs' sickness and organisational constraints (eg, inability to see their PCP in a timely manner) as legitimate reasons to visit the ED. However, although they found FUEDs' ED visits legitimate in many contexts, U-PCPs often questioned ED adequacy of caring for them. Yet, U-PCPs also questioned their own ability to care for FUEDs.

On the one hand, U-PCPs felt that the short time they spent at Unisanté, coupled with their overbooked consultations, did not enable them to create a trusting relationship with FUEDs and 'efficiently help them' (U-PCP11). On the other hand, U-PCPs felt that they were better positioned to provide comprehensive care for FUEDs compared with PP-PCPs, given the resources available at Unisanté, which were not available in private practices (eg, translators).

\section{PP-PCPS}

PP-PCPs also reported different challenges when caring for FUEDs. System-related challenges included loss of revenue when FUEDs failed to pay their bills, and time limitations placed on patients' encounters. Another challenge regarded lack of space/infrastructure, especially for PP-PCPs working alone/in small group practices, that prevented them from providing supportive care (ie, patient observation for a few hours). Collaborationrelated challenges included lack of communication, and information sharing with other healthcare providers (especially inpatient wards, but also the ED), and the time-consuming task of gathering information and coordinating care. These challenges negatively affected PP-PCPs, who felt 'powerless' (PP-PCP13) and 'frustrated' (PP-PCP5). However, PP-PCPs' did not question their ability to care for FUEDs and thought that most of their patients' ED visits reflected needs that were unmanageable in their practice.

ED visits, which were unmanageable in a practice, included complications of disease conditions (eg, cancer), a need for ED technical skills, the patient being in distress/crisis and/or the PCP being unavailable to handle the emergency (eg, weekend). These ED visits were considered legitimate since 'there was no other way of proceeding differently.' (PP-PCP12), and adequately handled in the ED. Visits concerning anxiety, social problems and substance abuse were considered more problematic, since they happened when the outpatient follow-up plan failed to meet FUEDs' needs. These visits were considered less effectively handled in the ED due to ED physicians' lack of time to address underlying social and structural factors contributing to these visits. Despite the many ED visits, PP-PCPs expressed feeling highly invested in their patients' care.

Most PP-PCPs explained having known their FUED patients for years, building over time a 'relationship of trust' (PP-PCP2), and considered themselves at the centre of their care. Through this role, PP-PCPs were able to absorb many FUED's urgent consultation needs, especially PP-PCPs working in group practices, who felt that their practice structure provided them with flexibility to facilitate their responsiveness for their patients. 
Table 2 Summary of themes related to primary care physicians (PCPs)' views of the care provided to frequent users of the emergency department (FUEDs) in emergency and primary care settings

\section{U-PCPs}

PP-PCPs

Challenges
"It is not easy because they [FUEDs] sometimes come at
hours that are not, let's say, working hours." (U-PCP4)
"I felt like they [migrant patients] were "consuming"
medical resources without really having a regular follow-
up. I felt that they didn't really understand our healthcare
system, (...) the purpose of having a follow-up." (U-PCP9)
"They were so many social issues that I sometimes felt
that I wasn't practicing medicine anymore, I was a social
worker." (U-PCP10)
"Sometimes, patients think that the PCP is omnipotent,
so it can be difficult. To make them understand that we
can't solve everything. (...) We have to deal with patients'
expectations that exceed what we can actually propose."
(U-PCP8)
legitimacy \& adequacy of care
"They were people who often didn't come to their appointments. (...) And when they had an acute problem, and it couldn't wait (...), they went to the ED." (U-PCP14)

- "The PCP changed every 6 months, every year. So why not see somebody else, but at the ED?" (U-PCP6)

- "We have patients, who are really multimorbid, who have a lot of acute diseases, who maybe go regularly to the ED for very justified reasons." (U-PCP3)

- "[ED] care might be poorer because it only addresses an $X$ or $Y$ question, purely in a biomedical manner, not at all from a biopsychosocial point of view." (U-PCP8)
$>$ (...) It's a major pitfall. Here, TARMED has it all wrong when it comes to vulnerable patients, for whom it is required sometimes to waste time to gain some." (PP-PCP16)

- "People working in hospitals tend to have a "crabs in a bucket" mentality. People are absent or we are not allowed to get their direct phone numbers, etc. It is a despairing waste of time and energy I have to say." (PP-PCP2)

- "I can't stay 4 hours with somebody. I mean, I can't go take care of other people and keep him [the patient] in the waiting room. In the ED, you can do that. (...) It might make you busy [keeping patients for medical examinations] but you can do it because there's enough space. In a primary care practice, it's just not possible. I mean, it can happen, half an hour if there's something you really need to do. But it's an exception." (PP-PCP6)

- "For somebody, who's severely dehydrated, with electrolyte disturbances, and underweighted, ambulatory means are extremely limited." (PP-PCP14)

- "The frequent and avoidable [ED] consultation should be targeted. Avoidable as it reflects a lack of adaptability of the follow-up framework for the person's actual problem." (PP-PCP12)

- "I think that the ED has neither time nor capacities to be efficient [for alcoholic FUEDs]. (...) Because when these patients arrive to the ED, they don't need medical care. All the work behind is understanding what started it all, why people drank, (...)" (PP-PCP8)

\begin{abstract}
Ability to provide care

- "The fact that residents [at Unisanté] are changing every 6 to 12 months does not enable adequate follow-up of that kind of patients." (U-PCP12)

"Is it fair that these patients have this kind of follow-up? Shouldn't they have a long-term follow-up?" (U-PCP11)

"But I think it is difficult to care for them [FUEDs] anywhere else [than Unisanté]. Things are hard to organize in a private practice. Translators cannot be organized. If they must be paid... But at Unisanté, costs are being taken care of." (U-PCP13)

- "Chief residents' supervision helped a lot. And we also had the possibility to call chief residents specialized in vulnerable populations." (U-PCP8)
\end{abstract}

"(...) play the role of an ally to the patient, to understand what's happening, synthesize and orientate the patient according to (his/her) symptoms, instead of the patient going here and there. If there's really the need for a second opinion, it is better that I accompany the patient, instead of care being completely scattered." (PP-PCP2)

- "A basic rule of our practice functioning [group practice] is that every emergency will be seen during the day or the next day. We aim at a $100 \%$ answering to emergencies." (PP-PCP9 [working in a group practice])

ED, emergency department; PP-PCPs, PCPs working in private practice; U-PCPs, PCPs at Unisanté.

\section{PCPs' views of the CMT intervention and the CMT}

See table 3 for a summary of the main themes that emerged in subsection 2 with illustrative quotes.

\section{U-PCPs}

Many U-PCPs, especially the ones who worked for more than a year at Unisanté, were satisfied with their collaboration with the CMT. They described a 'motivated, committed team' (U-PCP14), and felt 'less alone in the boat' (U-PCP5) caring for FUEDS due to CMT support, expertise, and knowledge of relevant local resources. U-PCPs found that the CMT letter provided a complete overview of their patients' situations, helping them focus on their identified needs (see online supplemental appendix 3 for a letter outline). In terms of impact, some U-PCPs found that the intervention significantly reduced their patients' level of anxiety and helped address social problems faced by FUEDs.

Other U-PCPs, especially those who stayed for a short period at Unisanté, regretted the lack of information they were provided regarding CMT activities, and lack of contact with the CMT throughout the intervention. Consequently, they felt unsure about contacting the CMT and perceived the team as another specialised 
Table 3 Summary of themes related to primary care physicians (PCPs)' views of the case management team (CMT) intervention and the CMT

\section{U-PCPs}

"It can be good sometimes just to talk in the corridor. And in a place like this [Unisanté], it's not complicated. There were many moments where we could see each other." (U-PCP4)

- "It helps relieve the doctor of the social aspect, that bothers us because we want to practice medicine. Plus, we don't have the knowledge, so we can feel powerless. Being able to give the leadership on social aspects to a team that was trained on those aspects, it relieves us and enables us to focus on medical aspects." (U-PCP12)

- "There were many social problems, mostly because he was migrant. The CMT was able to help him a lot with that." (U-PCP12)

\section{PP-PCPs}

-I greatly appreciated that the CMT was mobile, could come to my practice, and was available by e-mail or by phone. It allowed me to keep handling my chronic work overload, while still being able to sometimes focus on things other than somatic, such as those patients without having to leave the practice or devote an entire afternoon to them." (PP-PCP9)

- "I think that they [the team] did a great job... to investigate, to understand. They were really listening to the patient. And I found it good that the patient went to see this team in an organized manner. And these people had time, because I think that time is needed [for these patients]." (PP-PCP5)

\section{Negative}

aspects
- "It's like there were 2 parallel systems [CMT and PCPs]. Because we didn't necessarily see each other at the beginning of care and, from time to time, we would exchange a few words. (...) it felt like specialized care." (U-PCP8)

- Yes, there weren't many contacts. And I had a hard time understanding where they [CMT] were... so geographically, I had a hard time understanding where they were. And it didn't help me figure out what was their role in all that." (U-PCP9)

- "It [CMT role] felt essential but unclear. I didn't know when and whom I should turn to." (U-PCP10)

- "I don't remember it [CMT intervention] having had a big impact on care." (U-PCP11)
- "I felt like this letter fell down from the sky, and I've had already organized so much. (...) so, I didn't contact them back." (PP-PCP2)

- "I have to say that I didn't really have contacts with them [the team]. (...) I received the letter, but nothing else." (PP-PCP7)

- "This intervention [by the team], could it not have been undertaken by the psychiatrist? She [the patient] also has a follow-up by a psychiatry nurse. So, I don't know to what extent the job's been done twice. (...) What's the added value [of the CM intervention here], that's something I'm wondering about." (PP-PCP13)

- "But I couldn't understand how to use this service [the CMT] because I didn't really experience it. So, I don't really have the knowledge of how it works, if I can, maybe, ask for this intervention." (gPP-PCP5)

PP-PCPs, PCPs working in private practice; U-PCPs, PCPs at Unisanté.

unit. None of these U-PCPs knew what impact the CM intervention had on their FUED patients' situation.

\section{PP-PCPS}

PP-PCPs who remembered their collaboration with the CMT, emphasised its expertise, availability and mobility. They felt well supported, although one PCP regretted the abrupt, unclear cessation of the intervention.

However, most PP-PCPs did not have any recollection of their collaboration with the CMT. They related it to their limited contacts with the team during the intervention and their lack of knowledge of CMT activities. In this context, they found that the CMT letter, although well written and comprehensive, did not provide them with much support, since it represented an isolated contact and not a part of a broader collaboration. Some were also questioning the benefit of the CMT intervention, arguing that their patients already had many healthcare providers and extensive care supports.

\section{PCPs' suggestions to improve FUEDs' care}

See table 4 for a summary of the main themes that emerged in subsection 3 with illustrative quotes.

\section{U-PCPs}

Although U-PCPs agreed that no 'magical solution' (U-PCP3) existed due to FUEDs' inherent medical and social complexity, they made different suggestions to improve FUEDs' care.

First, U-PCPs proposed an enhanced feature of the computer system shared by the ED and Unisanté: automatic alerts informing U-PCPs of their patients' ED visits and a special, easily identifiable space to write information about FUEDs to be shared between healthcare providers to better coordinate care.

Second, U-PCPs recognised that increasing their availability might help address some of FUED's urgent consultation needs and proposed adding emergency slots to their clinic schedule.

Third, U-PCPs saw tighter collaboration between stakeholders caring for FUEDs as a key to providing better care. They emphasised the need to conduct regular meetings with key stakeholders, which would help FUEDs identify each stakeholder's role and ensure stakeholders have a common understanding of FUEDs' individual needs. Most U-PCPs were satisfied with their collaboration with the ED, although some wanted to be notified of their patients' ED visits quicker to establish a shared care plan. Regarding collaboration with the CMT, U-PCPs proposed that CMT activities be made more visible, thus encouraging them to contact the team. U-PCPs also wanted to have meetings with their patients and the CMT after initial evaluation by the team, so that 'clear objectives could be set' (U-PCP12) and 
Table 4 Summary of themes related to primary care physicians (PCPs)' suggestions to improve frequent users of the emergency department (FUEDs)' care

\section{U-PCPs}

Computer system
Increase availability
so we know what's actually going on." (U-PCP13)
"When they come to the ED], patients are automatically triaged to the ED. Couldn't we plan a deferred
not sent to an emergency service to address (his/her) complaint" (U-PCP8)
"I think having meetings with the patient from time to time... so that the patient knows and can say
what's okay and what's not to everybody, so that we can make changes, but having all heard the same
things. Because with separate consultations, patients don't always say the same things." (U-PCP6)
"For people who come a lot [to the ED], we've started protocols to try having coordinated care. But
people often visit the ED 20 times before it's put in place." (U-PCP3)
"I think that the PCP has to be convinced that it is useful [CMT care]. And that (he/she) knows what
they [the team] can propose. Because when we don't know, we think "one more thing to do, more
paperwork". And if we know what the services are, who are the people we are working with, it helps
succeeding as a team." (U-PCP14)
"It facilitates communication [having a case manager in the staff of PCPs], that's for sure. Because if it
is always the same person, we can quickly say something about a patient, even if we're meeting to talk
about another patient." (U-PCP12)
"With this way of functioning ([in Unisanté], maybe having somebody else, who would be in charge of
this part [social part] would help ensure a better follow-up to the patient... because every 6 months,
each year or 1.5 year, the PCP will change. So, there's information loss also." (U-PCP6)
"Somebody who would stay longer than the PCPs. A medical assistant or a social worker could create
a bond." (U-PCP11)

\section{PP-PCPs}

Enhance collaboration

- "We [ED and PCP] put a protocol in place so that every time the patient comes to the ED, he has the same [treatment]. And I think that this protocol is really good. (...) At least the doctor and the nurse caring for this patient at 3 am don't have to think about what to do. And it is not at 3 am that we should decide if we give him morphine and in what quantities. This should be decided beforehand. (...) It's a chronical pathology, we shouldn't decide every night what we should do." (PP-PCP5)

- "And coordinate the whole thing [FUEDs' healthcare team]. With the patient in the middle. The patient must be present [during the meeting]. That (he/she) feels that people work together. They [the patients] don't like it when one specialist says one thing, another something else. (...) They are lost. (...) We must work together. And there should be somebody to coordinate it all. It can be the PCP or somebody else, it doesn't matter. But everybody should be fine with the decision." (PP-PCP4)

- "I think for the CMT, it is important to see if there is a PCP and if (she/he) is used. Or here... if there's already a healthcare team... to see what's already in place... Instead of everybody doing things apart from each other." (PP-PCP2)

Case manager adequacy
"There should be a volume [of patients] big enough to warrant having somebody [case manager] in the
practice. It can be good for big infrastructures, who have many of those patients. But for a practice
where the PCP is alone, I think it is completely exaggerated." (PP-PCP7 [working alone in a practice])
"If we could delegate case management in the practice, it would be extraordinary. Our medical
assistants partially do this job. But if we had a person, like for him [the FUED patient] for example, who
contacts the IPT ["Integration Pour Tous" - paralegal service], who contacts... I would have gained
time." (PP-PCP2 [working in a group practice])
Best care setting
"In big group practice ore medical centers, it is possible to plan an emergency room for small daily
hospitalizations or hospitalizations of a few hours." (PP-PCP14)

CMT, case management team ; ED, emergency department; PP-PCPs, PCPs working in private practice; U-PCPs, PCPs at Unisanté.

the patients appropriately referred to resources according to their needs (eg, social worker in case of social needs). When asked, most U-PCPs agreed that having a case manager directly in their staff would facilitate communication between care providers, the CMT and FUEDs.
Fourth, U-PCPs thought that FUEDs should have a reference person. Although they disagreed on the person (case manager, social worker, medical assistant, nurse), they agreed that this person had to be available, and committed on the long-term to help foster trusting relationships with 
FUEDs and care providers, help with care coordination, and reduce the risk for information loss.

\section{PP-PCPS}

Like U-PCPs, PP-PCPs explained that there was 'no miracle recipe' (PP-PCP13) to address FUEDs' needs. However, PP-PCPs saw many ways to enhance FUEDs' care.

First, PP-PCPs wished for a quicker identification of FUEDs in the ED, coupled with a clear sign in those patients' files-'like an allergy' (PP-PCP12)—informing that they needed special care due their frequent use of healthcare services.

Second, PP-PCPs thought that closer collaboration and good communication with FUEDs' other healthcare providers, especially the CMT and the ED, were essential to ensure adequate care. As such, PP-PCPs wished that the ED staff would act as an integral part of FUEDs' healthcare team, discussing FUEDs' care needs with other members of the healthcare team to create a joint care protocol. PP-PCPs who had created a joint care protocol with the ED were very satisfied and reported a significant improvement of care coordination. Regarding collaboration with the CMT, PP-PCPs wished to be better informed of CMT activities. They also wanted to be contacted by a CMT member before the start of the intervention, asked their opinion about the necessity of an intervention, and invited to a meeting with the patient and the team at the beginning of the intervention.

Third, PP-PCPs working alone or in group practices differed in their willingness to welcome a case manager into their practice. PP-PCPs working alone found that they lacked space and the number of FUEDs to warrant the presence of an in-house case manager. PP-PCPs from group practices were more enthusiastic about welcoming a case manager into their team to facilitate care coordination and address social complexities. However, some recognised that 'delegating to somebody else could be complex' (PP-PCP13).

Fourth, some PP-PCPs thought that very complex patients with important social or psychiatric problems, or migration background, would access better care at outpatient clinics or in medical centres where there were more resources and staff to accommodate unscheduled and frequent visits.

\section{DISCUSSION}

Both U-PCPs and PP-PCPs thought that most FUEDs' ED visits were legitimate but questioned the EDs' adequacy to meet FUEDs' needs. Yet, both PCP groups reported encountering significant challenges in caring for FUEDs. In this context, U-PCPs seemed to benefit most from CMT involvement in supporting FUEDs' care needs in their practice compared with PP-PCPs, who seemed more satisfied with the care they were already providing. To enhance FUEDs' care, U-PCPs and PP-PCPs both suggested enhancing collaboration with other healthcare providers, notably ED staff and the CMT. U-PCPs and PP-PCPs working in group practices were willing to work more closely with a case manager. U-PCPs also wished to increase their availability, and some PP-PCPs considered outpatient clinics, larger group practices or medical centres most appropriate to handle FUEDs' needs.

In our study, U-PCPs and PP-PCPs found most FUEDs' ED visits legitimate, which is supported by previous studies asserting that FUEDs' frequent ED visits are largely appropriate given their important healthcare needs. ${ }^{78}$ Yet, U-PCPs and PP-PCPs expressed that ED visits for somatic reasons were more justified and better taken care of in the ED than visits for non-urgent health problems or psychosocial concerns. For these types of issues, it is generally agreed that FUEDs are better served in primary care settings, designed to offer them the required continuity of care. ${ }^{29-31}$ Furthermore, primary care practices often represent the first point of access to the healthcare system, ${ }^{20}$ particularly in Switzerland where they act as reference centres. ${ }^{32}{ }^{33}$ Hence, PCPs are in the optimal position to competently oversee care and refer FUEDs to relevant multi-disciplinary care providers. However, our findings reveal that caring for FUEDs in primary care settings is fraught with challenges. U-PCPs reported organisational and structural challenges that made them question their ability to care for FUEDs, and were seen as reasons for FUEDs to visit the ED. Supporting this assertion, one study found that dissatisfaction with treatment and accessibility to primary care was one of patients' main reasons to self-refer to the ED. ${ }^{34}$ PP-PCPs, although also reporting many challenges, did not seem to question their ability to care for FUEDs as much as U-PCPs. This might coincide with the trusting relationship most PP-PCPs claimed to have developed with their FUED patients, showing the importance of patient-healthcare provider relationship. ${ }^{35}$ The fact that U-PCPs and PP-PCPs found the ED ill-adapted to meet many FUEDs' needs, but faced themselves many challenges in their care likely highlights the complexity of caring for this patient population, whose 'suffering is considered unique and cannot be fully understood, even by authority on illness, such as a family doctor'. ${ }^{36}$

In this context, $\mathrm{CM}$ interventions have been shown to be particularly relevant, since they 'respond to the complex needs of a very vulnerable clientele through a structured approach that promotes self-management support and better integration of healthcare services' ${ }^{37}$ Furthermore, $\mathrm{CM}$ interventions aim at fostering communication and collaboration between the different stakeholders involved in FUEDs' care, ${ }^{13}$ which U-PCPs and PP-PCPs reported to be challenging, and the $\mathrm{CM}$ intervention created in Lausanne particularly aimed to include PCPs, reinforcing their role in FUEDs' care. However, some U-PCPs' regretted the slow onset of collaboration and limited information sharing with the CMT, and most PP-PCPs' lacked recollection of collaborating with the CMT. This raises questions as to whether meaningful collaboration was achieved and likely reflects that this particular CM 
intervention is hospital-based ${ }^{15}$ and therefore less integrated into community-based primary care settings.

To improve FUEDs' care, U-PCPs and PP-PCPs both emphasised the need for greater collaboration and coordination with other stakeholders involved in FUEDs' care, especially ED staff and the CMT. Reinforcing the importance of healthcare providers' collaboration in CM interventions, a systematic review by Hudon $e t$ al, showed that establishing multidisciplinary care plans for frequent users of healthcare was associated with positive outcomes in $\mathrm{CM}$ interventions. ${ }^{13}$ Emphasising the importance of care coordination, another study, which identified a group of primary care frequent users that was named 'frequent users with unmet healthcare needs', argued that it was not access to care but coordination between healthcare providers that prevented frequent users to meet their needs. ${ }^{38}$ Another suggestion to improve FUEDs' care, although slightly differing between U-PCPs and PP-PCPs, lies in primary care itself, as it implies a change in its structure and functioning. For instance, finding a way to enhance U-PCPs' availability and flexibility, that is, emergency slots in U-PCPs' planning, is one solution. Finding a way to appropriately compensate PP-PCPs who care for FUEDs and fostering interprofessional collaboration within practices (eg, with a case manager) could be another solution. Furthermore, some PP-PCPs expressed that perhaps FUEDs are better suited as patients in larger primary care practices that, given their larger and often multi-disciplinary staff, are better equipped to address the complexity of their needs and better able to accommodate unscheduled visits.

Overall, enhancing FUEDs' care requires an integrated, coordinated and adaptive framework of care. Hence, future research should focus on exploring ways to improve communication between PCPs and ED physicians, for example, shared care plans. Additionally, a follow-up mirror study, addressing issues faced by the CMT or ED physicians in their collaboration with PCPs would be essential to find common solutions. It would also be valuable to investigate solutions to expand the scope of CMT from hospital-based interventions to broader community-based interventions with greater involvement of PCPs practicing in the community. Finally, research at the health policy level could explore ways of adapting current models of care delivery structures and compensation to better support, and even incentivise, PCPs to provide optimal care to their FUED patients whose needs differ from the general population.

\section{Strengths and limitations}

The main strength of this study is the novelty it brings to the existing literature regarding FUEDs by focusing on PCPs' perceptions. Indeed, there has been little research so far on PCPs' experience caring for FUEDs in primary care, despite PCPs playing such an integral role in their care.

However, this study has several limitations that require consideration. First, selecting PCPs who had contact with the CMT between 2010 and 2018 may have led to a recall bias. PCPs who had earlier contact with the CMT may have been more likely to forget pertinent information than those with more recent contact. Second, the study findings are based on the described CM intervention implemented in the Canton of Vaud, a context which may differ from other CM interventions. Though other contexts might involve different types of PCPs with varying relationships and communication modes between PCPs, CMT members and ED physicians, what PCPs thought of the overall care provided to FUEDs and their many suggestions to improve FUEDs' care appear generalisable among diverse contexts. That findings may be generalisable beyond our local context is further supported by the fact that similar themes emerged among U-PCPs and PP-PCPs interviewed in our study despite their very disparate practice contexts.

\section{CONCLUSIONS}

This study provides unique and novel insights into the perceptions of PCPs as key stakeholders in FUEDS' care whose views are seldom heard amidst the growing literature on FUEDs and CM interventions. This study highlights the many challenges PCPs face in caring for FUEDs, although differing form U-PCPs to PP-PCPs, that a CM intervention has the potential to mitigate by facilitating shared responsibility and improved collaboration in the provision of FUEDs' care. However, PCPs, especially PP-PCPs, expressed a desire for closer collaboration with the CMT. Establishing improved integration of CMTs into community-based primary care settings is a promising way forward in improving FUEDs' care. Other promising solutions requiring further exploration are the reinforcement of collaboration between ED physicians and PCPs, as well as a change of structure and functioning of primary care practices in better addressing FUEDs' needs.

\section{Author affiliations}

${ }^{1}$ Department of Vulnerabilities and Social Medicine, Unisanté, Lausanne, Vaud, Switzerland

${ }^{2}$ Department of Medicine, University of Calgary Faculty of Medicine, Calgary, Alberta, Canada

${ }^{3}$ Family Medicine and Emergency Medicine Department, Université de Sherbrooke, Sherbrooke, Quebec, Canada

${ }^{4}$ Department of Family Medicine, Unisanté, Lausanne, Vaud, Switzerland ${ }^{5}$ Emergency Department, University Hospital of Lausanne, Lausanne, Vaud, Switzerland

${ }^{6}$ Department of Epidemiology and Health Systems—University of Lausanne, Unisanté, Lausanne, Vaud, Switzerland

Acknowledgements The authors wish to thank the primary care providers, who participated in the interviews, and the case management team for their contribution and participation to the collection of the data.

Contributors $\mathrm{LB}, \mathrm{CH}, \mathrm{CA}$ and $\mathrm{PB}$ designed the study. $\mathrm{LB}$ conducted the 30 interviews. $L B$ and MCA analysed the data. $L B$ and MM lead the writing of the manuscript. NS, $\mathrm{OH}, \mathrm{FV}$ and $\mathrm{PB}$ participated in the creation of the interview grid. $\mathrm{CA}$ and PB supervised the whole study. All authors reviewed and gave feedback as well as final approval to submit the manuscript.

Funding The authors have not declared a specific grant for this research from any funding agency in the public, commercial or not-for-profit sectors. 
Competing interests None declared.

Patient consent for publication Not required.

Ethics approval The study was approved by the Human Research Ethics Committee of the Canton of Vaud, Switzerland (Req-2018-01058).

Provenance and peer review Not commissioned; externally peer reviewed.

Data availability statement Data are available upon reasonable request. Due to the collecting method (interviews in French), raw data cannot be shared. However, they can be provided upon request to the corresponding author for comparison in future research. Supplementary data to further describe the CM intervention can be found in the appendices.

Supplemental material This content has been supplied by the author(s). It has not been vetted by BMJ Publishing Group Limited (BMJ) and may not have been peer-reviewed. Any opinions or recommendations discussed are solely those of the author(s) and are not endorsed by BMJ. BMJ disclaims all liability and responsibility arising from any reliance placed on the content. Where the content includes any translated material, BMJ does not warrant the accuracy and reliability of the translations (including but not limited to local regulations, clinical guidelines, terminology, drug names and drug dosages), and is not responsible for any error and/or omissions arising from translation and adaptation or otherwise.

Open access This is an open access article distributed in accordance with the Creative Commons Attribution Non Commercial (CC BY-NC 4.0) license, which permits others to distribute, remix, adapt, build upon this work non-commercially, and license their derivative works on different terms, provided the original work is properly cited, appropriate credit is given, any changes made indicated, and the use is non-commercial. See: http://creativecommons.org/licenses/by-nc/4.0/.

\section{ORCID iDs}

Laureline Brunner http://orcid.org/0000-0003-0397-7696

Catherine Hudon http://orcid.org/0000-0001-6140-9916

Olivier Hugli http://orcid.org/0000-0003-2312-1625

\section{REFERENCES}

1 LaCalle E, Rabin E. Frequent users of emergency departments: the myths, the data, and the policy implications. Ann Emerg Med 2010;56:42-8.

2 Bodenmann P, Baggio S, Iglesias K, et al. Characterizing the vulnerability of frequent emergency department users by applying a conceptual framework: a controlled, cross-sectional study. Int J Equity Health 2015;14:146.

3 Althaus F, Stucki S, Guyot S, et al. Characteristics of highly frequent users of a Swiss academic emergency department: a retrospective consecutive case series. Eur J Emerg Med 2013;20:413-9.

4 Milbrett P, Halm M. Characteristics and predictors of frequent utilization of emergency services. J Emerg Nurs 2009;35:191-8.

5 Byrne M, Murphy AW, Plunkett PK, et al. Frequent attenders to an emergency department: a study of primary health care use, medical profile, and psychosocial characteristics. Ann Emerg Med 2003;41:309-18.

6 Hunt KA, Weber EJ, Showstack JA, et al. Characteristics of frequent users of emergency departments. Ann Emerg Med 2006;48:1-8.

7 Krieg C, Hudon C, Chouinard M-C, et al. Individual predictors of frequent emergency department use: a scoping review. BMC Health Serv Res 2016;16:594

8 Althaus F, Paroz S, Hugli O, et al. Effectiveness of interventions targeting frequent users of emergency departments: a systematic review. Ann Emerg Med 2011;58:e42:41-52.

9 Cunningham A, Mautner D, Ku B, et al. Frequent emergency department visitors are frequent primary care visitors and report unmet primary care needs. J Eval Clin Pract 2017;23:567-73.

10 Hudon C, Chouinard M-C, Lambert M, et al. Key factors of case management interventions for frequent users of healthcare services: a thematic analysis review. BMJ Open 2017;7:e017762.

11 Hudon C, Sanche S, Haggerty JL. Personal characteristics and experience of primary care predicting frequent use of emergency department: a prospective cohort study. PLoS One 2016;11:e0157489.

12 Hudon C, Chouinard M-C, Lambert M, et al. Effectiveness of case management interventions for frequent users of healthcare services: a scoping review. BMJ Open 2016;6:e012353.
13 Hudon C, Chouinard M-C, Pluye P, et al. Characteristics of case management in primary care associated with positive outcomes for frequent users of health care: a systematic review. Ann Fam Med 2019;17:448-58.

14 Vaud Cd. STATISTIQUE VAUD - Statistique annuelle de la population vaudoise au 31.12.2019, 2019. Available: http://www.scris.vd.ch/ default.aspx?docID $=7837$

15 Bodenmann P, Velonaki V-S, Griffin JL, et al. Case management may reduce emergency department frequent use in a universal health coverage system: a randomized controlled trial. J Gen Intern Med 2017;32:508-15.

16 Locker TE, Baston S, Mason SM, et al. Defining frequent use of an urban emergency department. Emerg Med J 2007;24:398-401.

17 Iglesias K, Baggio S, Moschetti K, et al. Using case management in a universal health coverage system to improve quality of life of frequent emergency department users: a randomized controlled trial. Qual Life Res 2018;27:503-13.

18 Canepa Allen M, Ansermet C, Schupbach J. Un accompagnement respectueux des priorités Du patient. Krankenpfl Soins Infirm 2014;6:62-5

19 Chan BTB, Ovens HJ. Frequent users of emergency departments. do they also use family physicians' services? Can Fam Physician 2002;48:1654-60.

20 Hudon C, Chouinard M-C, Dubois M-F, et al. Case management in primary care for frequent users of health care services: a mixed methods study. Ann Fam Med 2018;16:232-9.

21 Bradshaw C, Atkinson S, Doody O. Employing a qualitative description approach in health care research. Glob Qual Nurs Res 2017;4:233339361774228.

22 Hudelson P. La Recherche qualitative en médecine de premier recours. Rev Med Suisse 2004.

23 FMH. TARMED : Navigateur tarifaire et banque de données, 2019. Available: https://www.fmh.ch/fr/themes/tarifs-ambulatoires/ navigateur-tarifaire-donnees.cfm

24 Sandelowski M. Sample size in qualitative research. Res Nurs Health 1995;18:179-83.

25 Kivits J, Balard F, Fournier C. Les Recherches qualitatives en santé: Armand colin, 2016: 329.

26 Burnard P, Gill P, Stewart K, et al. Analysing and presenting qualitative data. Br Dent J 2008;204:429-32.

27 Vaismoradi M, Turunen $\mathrm{H}$, Bondas T. Content analysis and thematic analysis: implications for conducting a qualitative descriptive study. Nurs Health Sci 2013;15:398-405.

28 Bieler G, Paroz S, Faouzi M, et al. Social and medical vulnerability factors of emergency department frequent users in a universal health insurance system. Acad Emerg Med 2012;19:63-8.

29 Huang J-A, Weng R-H, Lai C-S, et al. Exploring medical utilization patterns of emergency department users. J Formos Med Assoc 2008;107:119-28.

30 Hansagi H, Olsson M, Sjöberg S, et al. Frequent use of the hospital emergency department is indicative of high use of other health care services. Ann Emerg Med 2001;37:561-7.

31 Singer A, Kosowan L, Katz A, et al. Characterizing patients with high use of the primary and tertiary care systems: a retrospective cohort study. Health Policy 2020;124:291-7.

32 Biller-Andorno N, Zeltner T. Individual responsibility and community solidarity--the Swiss health care system. N Engl J Med 2015;373:2193-7.

33 Blendon RJ, Benson JM, Hero JO. Public trust in physicians-U.S. medicine in international perspective. $N$ Engl J Med 2014;371:1570-2.

34 Diserens L, Egli L, Fustinoni S, et al. Emergency department visits for non-life-threatening conditions: evolution over 13 years in a Swiss urban teaching hospital. Swiss Med Wkly 2015;145:w14123.

35 Ahmad I, Nawaz A, Khan S. Predictors of patient satisfaction. Gomal J Med Sci 2011;9.

36 Hodgson P, Smith P, Brown T, et al. Stories from frequent attenders: a qualitative study in primary care. Ann Fam Med 2005;3:318-23.

37 Hudon C, Chouinard M-C, Diadiou F, et al. Case management in primary care for frequent users of health care services with chronic diseases: a qualitative study of patient and family experience. Ann Fam Med 2015;13:523-8.

38 Senn N, Cohidon C, Breton M, et al. Patterns of patient experience with primary care access in Australia, Canada, New Zealand and Switzerland: a comparative study. Int J Qual Health Care 2019;31:G126-32. 